\title{
Physiological Monitoring in Diving Mammals
}

\author{
Andreas Fahlman \\ Department of Life Sciences Texas A\&M- Corpus Christi \\ 6300 Ocean Dr. Unit 5892 \\ Corpus Christi, TX 78412 \\ phone: (361) 825-3489 fax: (361) 825-2025 email: andreas.fahlman@tamucc.edu \\ Peter L. Tyack \\ School of Biology, Sea Mammal Research Unit, Scottish Oceans Institute \\ University of Saint Andrews \\ Saint Andrews, Fife KY16 8LB UK \\ phone: (508) 289-2818 email:ptyack@whoi.edu \\ Michael Moore \\ Woods Hole Oceanographic Institution \\ 266 Woods Hole Road, MS \#50 \\ Woods Hole, MA 02543 \\ email:mmoore@whoi.edu \\ Warren Zapol and Richard Anderson \\ Departments of Anesthesia, Critical Care, Cardiology and Dermatology \\ Harvard Medical School at Massachusetts General Hospital \\ Boston, Massachusetts 02114 \\ email:wzapol@partners.org \\ email :rranderson@partners.org \\ Steve Trumble \\ Baylor University \\ One Bear Place \#97388 \\ Waco, TX 76798-7388
}

Award Number: N00014-12-1-0187

\section{LONG-TERM GOALS}

The objective with this study is to develop and calibrate an invasive data logger to measure muscle $\mathrm{O}_{2}$ saturation in large, freely diving whales. We intend to use this data logger to measure muscle $\mathrm{O}_{2}$ saturation and determine how blood flow to muscle is altered during diving. These data will be important to determine if muscle blood flow is reduced during diving, and important to estimate how the dive response affects muscle $\mathrm{N}_{2}$ levels and the risk of decompression sickness (DCS). 


\section{Report Documentation Page}

Form Approved

OMB No. 0704-0188

Public reporting burden for the collection of information is estimated to average 1 hour per response, including the time for reviewing instructions, searching existing data sources, gathering and maintaining the data needed, and completing and reviewing the collection of information. Send comments regarding this burden estimate or any other aspect of this collection of information,

including suggestions for reducing this burden, to Washington Headquarters Services, Directorate for Information Operations and Reports, 1215 Jefferson Davis Highway, Suite 1204, Arlington

VA 22202-4302. Respondents should be aware that notwithstanding any other provision of law, no person shall be subject to a penalty for failing to comply with a collection of information if it

does not display a currently valid OMB control number.

1. REPORT DATE

30 SEP 2014

4. TITLE AND SUBTITLE

Physiological Monitoring in Diving Mammals

6. $\operatorname{AUTHOR}(\mathrm{S})$

7. PERFORMING ORGANIZATION NAME(S) AND ADDRESS(ES)

Texas A\&M- Corpus Christi,Department of Life Sciences,6300 Ocean Dr. Unit 5892,Corpus Christi,TX,78412

9. SPONSORING/MONITORING AGENCY NAME(S) AND ADDRESS(ES)

3. DATES COVERED

00-00-2014 to 00-00-2014

5a. CONTRACT NUMBER

5b. GRANT NUMBER

5c. PROGRAM ELEMENT NUMBER

5d. PROJECT NUMBER

5e. TASK NUMBER

5f. WORK UNIT NUMBER

8. PERFORMING ORGANIZATION

REPORT NUMBER

10. SPONSOR/MONITOR'S ACRONYM(S)

11. SPONSOR/MONITOR'S REPORT

$\operatorname{NUMBER}(S)$

12. DISTRIBUTION/AVAILABILITY STATEMENT

Approved for public release; distribution unlimited

13. SUPPLEMENTARY NOTES

14. ABSTRACT

15. SUBJECT TERMS

16. SECURITY CLASSIFICATION OF:

a. REPORT

unclassified b. ABSTRACT

unclassified c. THIS PAGE

unclassified
17. LIMITATION OF ABSTRACT

Same as

Report (SAR)
18. NUMBER 19a. NAME OF

OF PAGES RESPONSIBLE PERSON

11 


\section{OBJECTIVES}

This project is separated into three aims:

Aim 1: Develop a new generation of tags/data logger for marine mammals that will contain a sensor to be implanted into the muscle. The logger will collect physiological data from muscle tissue in freely diving marine mammals. The sensor will be tested and calibrated in terrestrial mammals at Massachusetts General Hospital, Boston (see Appendix for a detailed description and current progress for the work by MGH).

Aim 2: The data logger will be tested in freely diving marine mammals in the field, and muscle $\mathrm{O}_{2}$ saturation data will be collected.

Aim 3: Measure the concentration of aerobic/anaerobic enzymes, total myoglobin, and fiber type in muscle tissues of post-mortem stranded whales.

\section{APPROACH}

This project is separated into three aims: Aim 1a) Development of a new generation of tag/data logger for marine mammals that will contain a sensor to be implanted into the muscle. The logger will collect physiological data from muscle tissue in freely diving marine mammals. The sensor will be tested and calibrated in terrestrial mammals at Massachussetts General Hospital, Boston. The calibration in a terrestrial mammal model is based on the assumption that the absorption spectra is similar for all mammals, which was tested in this fiscal year; Aim 2) The data logger will be tested in freely diving marine mammals in the field, and muscle $\mathrm{O}_{2}$ saturation data will be collected; Aim 3) The aerobic and anaerobic enzyme and myglobin levels in the muscle of selected species will be measured. The latter is important to convert $\mathrm{O}_{2}$ saturation to $\mathrm{O}_{2}$ content.

Aim 1: A near infrared spectrophotometer connected to a data logging device will be developed and used to measure myoglobin/hemoglobin $\mathrm{O}_{2}$ saturation in freely deep diving whales (e.g. beaked whales, sperm whales). We are currently developing two different units, one based upon the succesful construction of an oximeter used in Weddel seals (Guyton, Stanek et al. 1995), and another using recent fiber optic technology. Additionally, a comparative study will be performed to test the assumption that terrestrial mammal blood (human) can be used to calibrate the sensor. Previous studies that have used NIR spectroscopy relied on the assumptions that the optical properties in terrestrial mammal hemoglobin are the same for marine mammals. Following the comparative study, the sensor will be calibrated in human blood in the Comparative Physiology Lab at Texas A\&M UniversityCorpus Christi (Corpus Christi, Texas). A delivery device was fabricated in the last fiscal year to allow implantation of the optical probe into the muscle of free diving marine mammals.

Aim 2: Develop a new generation of tags/data logger for marine mammals that will contain a sensor to be implanted into the muscle. The need for improvements to the initial data logger was discovered following the first field season with Northern elephant seals in April of 2013. Improvements will be made to the data logger unit with a new engineering firm and a second field season will be undertaken in the fall of 2015. The logger will collect physiological data from muscle tissue in freely diving marine mammals. 
Aim 3: Muscle tissues from deceased stranded whales (sperm and beaked whales) will be analyzed for aerobic/anaerobic enzymes, total muscle myoglobin concentration and fiber type.

\section{WORK COMPLETED}

\section{Aim 1: \\ Fiber optic oximetry technology \\ System Hardware Integration of Optical Fibers for Delivery and Detection of Light}

The light sources are two relatively small laser diodes (LD) and one avalanche photodetector (APD) that could be packaged in a $2 \mathrm{~cm}$ diameter by $5 \mathrm{~cm}$ length bullet probe. Because the system operates at $70 \mathrm{MHz}$, three relatively thick RF-shielded cable bundles would be required to power LDs and collect APD voltage. In order to maintain the minimally invasive feature of the optical probe, the light probing oxygen levels in muscle will be delivered and detected through optical fibers. Effectively reducing the size of the bullet probe to $<0.5 \mathrm{~cm}$ diameter by $5 \mathrm{~cm}$ length and eliminating the need for RF-shielded cables. The diameter of the cable feeding and reading the probe is defined by the thickness of the fibers and, if needed, a mechanical shielding jacket. During this reporting period we accomplished the system hardware integration of optical fibers for delivery and detection of light at 808 and $650 \mathrm{~nm}$. Figure 1 shows two optical fibers held by pin vises, one for the incident light and the other for the returning light. The fibers tips are immersed in an intralipid and ink mixture that simulates scattering and absorption in tissue, respectively. For detection, a compact lens system was designed and implemented to optically couple the light returning in a $365 \mu \mathrm{m}$ diameter multimode $0.22 \mathrm{NA}$ fiber onto the active area $(500 \mu \mathrm{m}$ diameter $)$ of the APD.

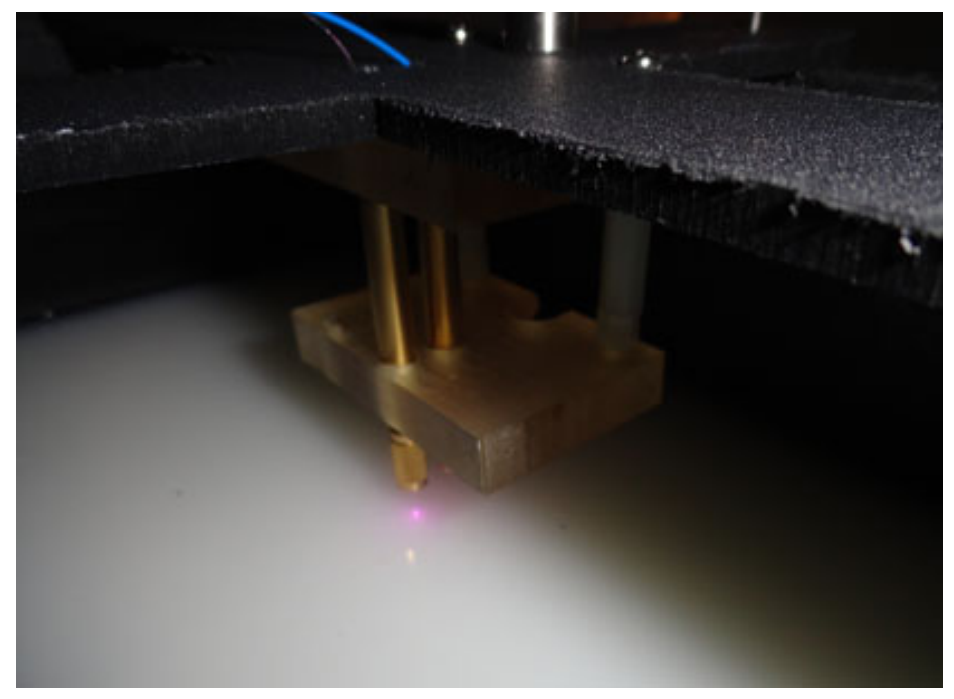

Figure 1. Optical Fibers for Delivery and Detection of Light

The use of a fiber resulted in a smaller input aperture size at the APD, which demanded a higher signal to noise ratio performance to compensate for this reduction in detection surface. To this end, we integrated a new APD module (C5331-02, Hamamatsu Japan) with a temperature-compensated bias voltage circuit and a stable gain as low as $2.5 \%$. 
System Hardware Design of RF Electronic Modules for Modulating Light Sources

Throughout the proof of concept phase we used a function generator to modulate and drive LDs. During this reporting period we evaluated different components for modulating and driving the LDs. As a result, the RF signal will be generated by a microcontroller (BeagleBone Black, Richardson TX) with an internal clock of $1 \mathrm{GHz}$ and $512 \mathrm{MB}$ of RAM capabilities, which allows us to generate a sinusoidal signal by creating a $70 \mathrm{MHz}$ squarewave signal and using a low-pass filter with $70 \mathrm{MHz}$ cutoff frequency to eliminate $2^{\text {nd }}$ and higher order harmonics. The generated sinusoidal signal will modulate the output current from a LD driver, effectively modulating the intensity of emission of the light source at $70 \mathrm{MHz}$, Figure 2. The chosen LD driver (LDS-VRM-005, Picolas, Germany) is the only commercial driver with variable pulse duration, an output current up to $500 \mathrm{~mA}, 3 \mathrm{~V}$ forward voltage, frequency response up to $100 \mathrm{MHz}$ and $-3 \mathrm{~dB}$ of power dissipation. These features are essential for modulating at high intensity and, subsequently, increasing the signal-to-noise ratio of the returning light, which in turn will allow us to resolve phase shifts as small as 0.1 degrees. Phase shifts correspond to changes in light absorption, which in muscle correspond to changes in oxygenation.

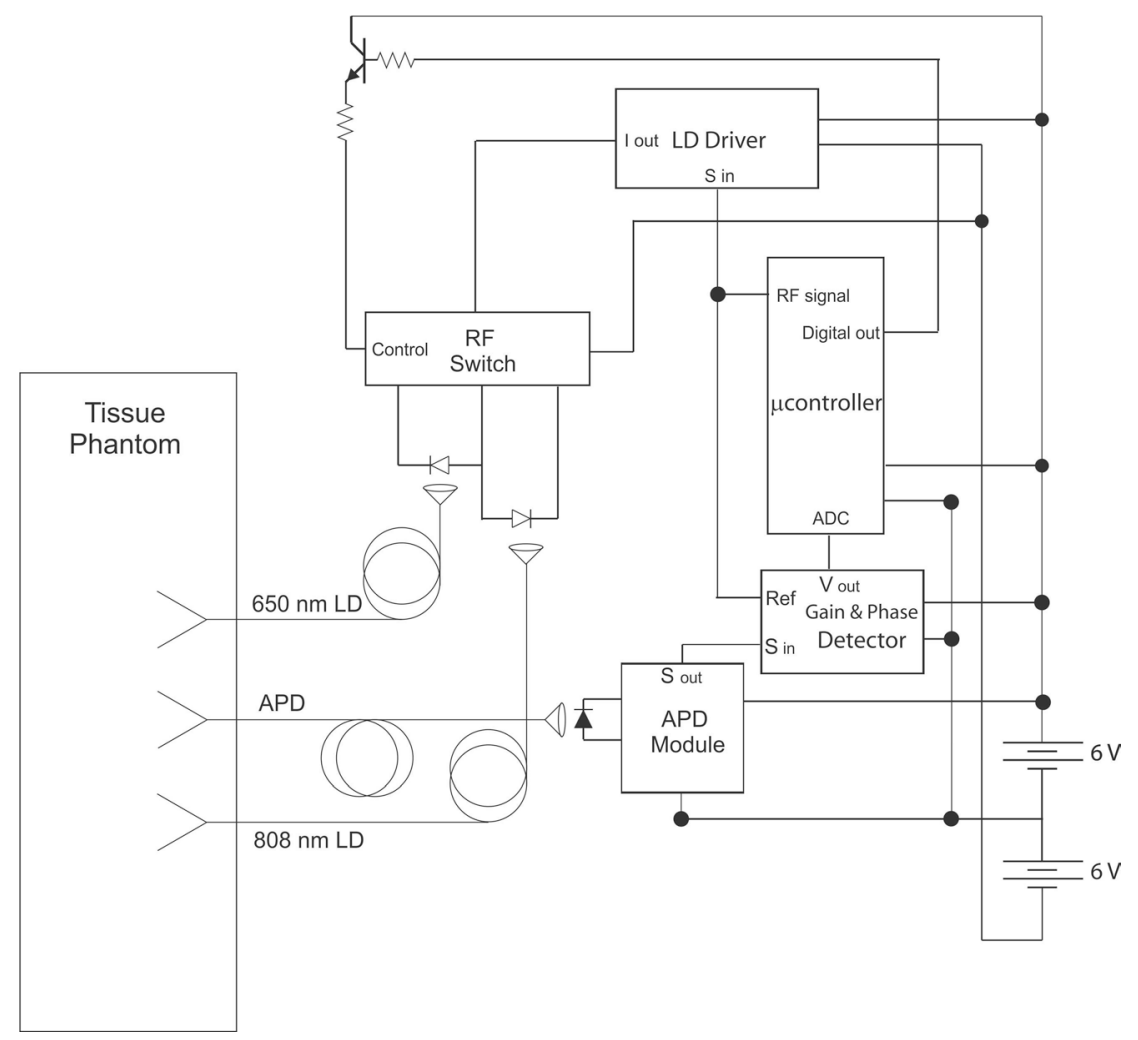

\section{Figure 2. Optical and RF Electronic Modules for Modulating Light Sources, Detecting Backscattered Light and Quantifying Phase Shifts}

Testing assumptions of hemoglobin absorption spectra

To test the assumptions that the absorption spectra are the same for all mammals, we conducted a comparative study of terrestrial (human, IRB 123-11) and marine mammal hemoglobin (AUP 12-02, $\mathrm{Hb}$ ) absorption spectra. For this purpose, we collected blood and isolated $\mathrm{Hb}$. The $\mathrm{Hb}$ was oxygenated and deoxygenated using a custom made tonometer, and the absorption spectra tested from $600 \mathrm{~nm}$ to $1000 \mathrm{~nm}$ using a spectrophotometer. The two spectra were overlaid to determine the isobestic point, the point where the spectra cross over (see below). Data from 5 marine mammal species (killer whale, 
beluga whale, pilot whale, and elephant seal) were compared aginst the human $\mathrm{Hb}$ absorption spectra and it was concluded that they were similar enough (see figure 4 below) to calibrate the oximeter sensor using human blood.

\section{Aim 2:}

Following the first field season in April, 2013, implantation and data collection using the sensor and the data logger were assessed. It was determined that improvements to the data logger were needed and a subsequent search for an engineering firm commenced. Further, the data from one of the data loggers has been analyzed and has supported our belief in the need for modifying the data loggers from the first field season.

\section{Aim 3:}

This aim was completed and the data written up and published in a PD thesis by Dr. Colby Moore.

\section{RESULTS}

\section{Aim 1:}

Fiber optic oximetry technology

The fiber optic technology will be tested in a sheep model and the sensor calibrated to allow us to estimate muscle $\mathrm{O}_{2}$ levels.

\section{Testing assumptions of hemoglobin absorption spectra}

When estimating blood $\mathrm{O}_{2}$ saturation using near-infrared (NIR) spectrophotometry, the absorbance of transmitted NIR radiation by $\mathrm{Hb}$ is measured. The absorption spectra for oxygenated hemoglobin $(\mathrm{HbO} 2)$ and reduced hemoglobin $(\mathrm{HbR})$ for humans were used as a comparions as they have been well characterized. The isobestic point, the point where the two absorption spectra ( $\mathrm{HbR}$ and $\mathrm{HbO} 2)$ crossover, is at $\sim 800 \mathrm{~nm}$ for human blood (Fig. 3). Oximeters used in marine mammals rely on the assumption that the $\mathrm{HbO} 2$ and $\mathrm{HbR}$ spectra and isobestic point are similar to humans. As marine vertebrates appear to have modified $\mathrm{Hb}$ to assist prolonged apnea (Meir and Ponganis 2009) this may also alter the optical properties of this protein. Therefore, the objective of this study was to determine the absorbance spectra of $\mathrm{HbO} 2$ and $\mathrm{HbR}$ in several species of marine mammals (orcas, short-finned pilot whales, belugas, and northern elephant seals) and compare these against humans. Whole blood samples were opportunistically obtained during health assessment blood collection and the Hb isolated via a series of centrifugation, dialysis, and filtration steps. The isolated $\mathrm{Hb}$ was oxygenated or deoxygenated using $5 \% \mathrm{CO}_{2}$ and $95 \% \mathrm{O}_{2}$ or $\mathrm{N}_{2}$, respectively. Under gas-tight conditions, the $\mathrm{HbO} 2$ and HbR samples were placed in a UV-visible light spectrophotometer and the absorption spectra measured from $600 \mathrm{~nm}$ to $1000 \mathrm{~nm}$. The absorption spectra were overlaid and the isobestic point determined. The results indicate the absorption spectra are similar between the species investigated and the isobestic point for $\mathrm{Hb}$ is $\sim 800 \mathrm{~nm}$ (Figs. 3 and 4). 


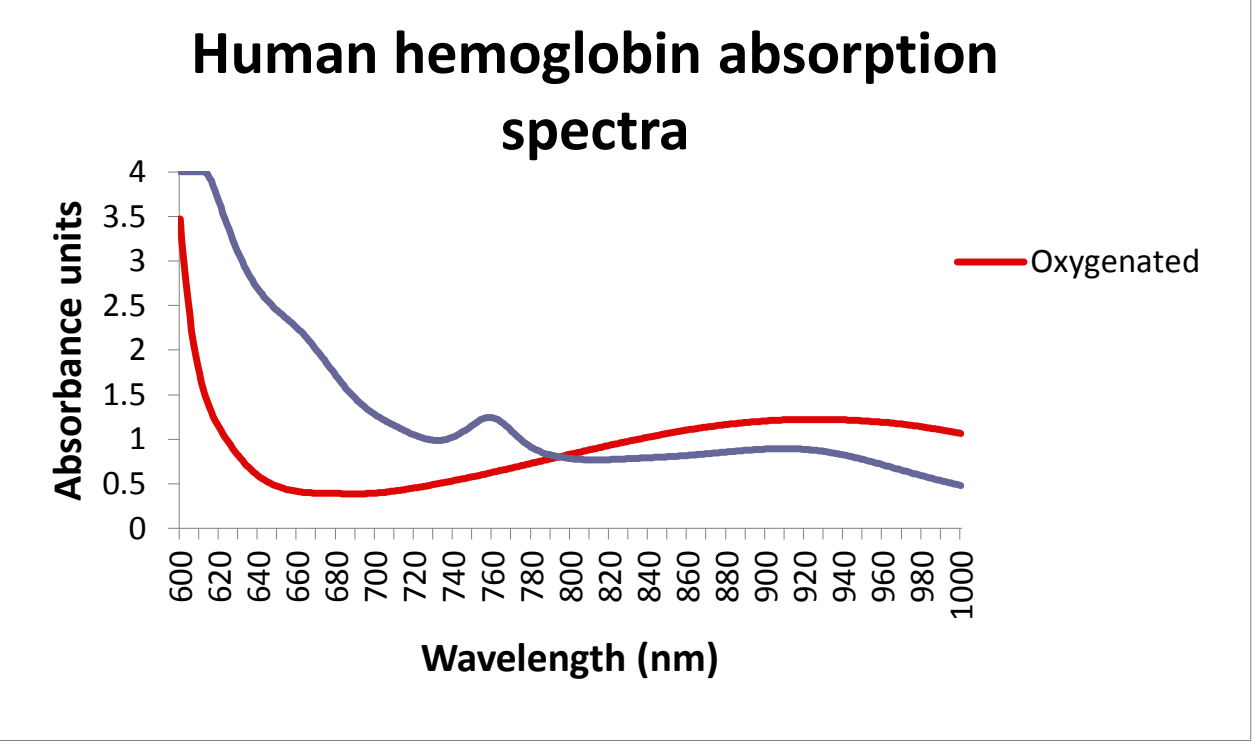

Figure 3. The human hemoglobin absorption spectra for oxygenated vs. deoxygenated blood with an isobestic point of $\sim 800 \mathrm{~nm}$.

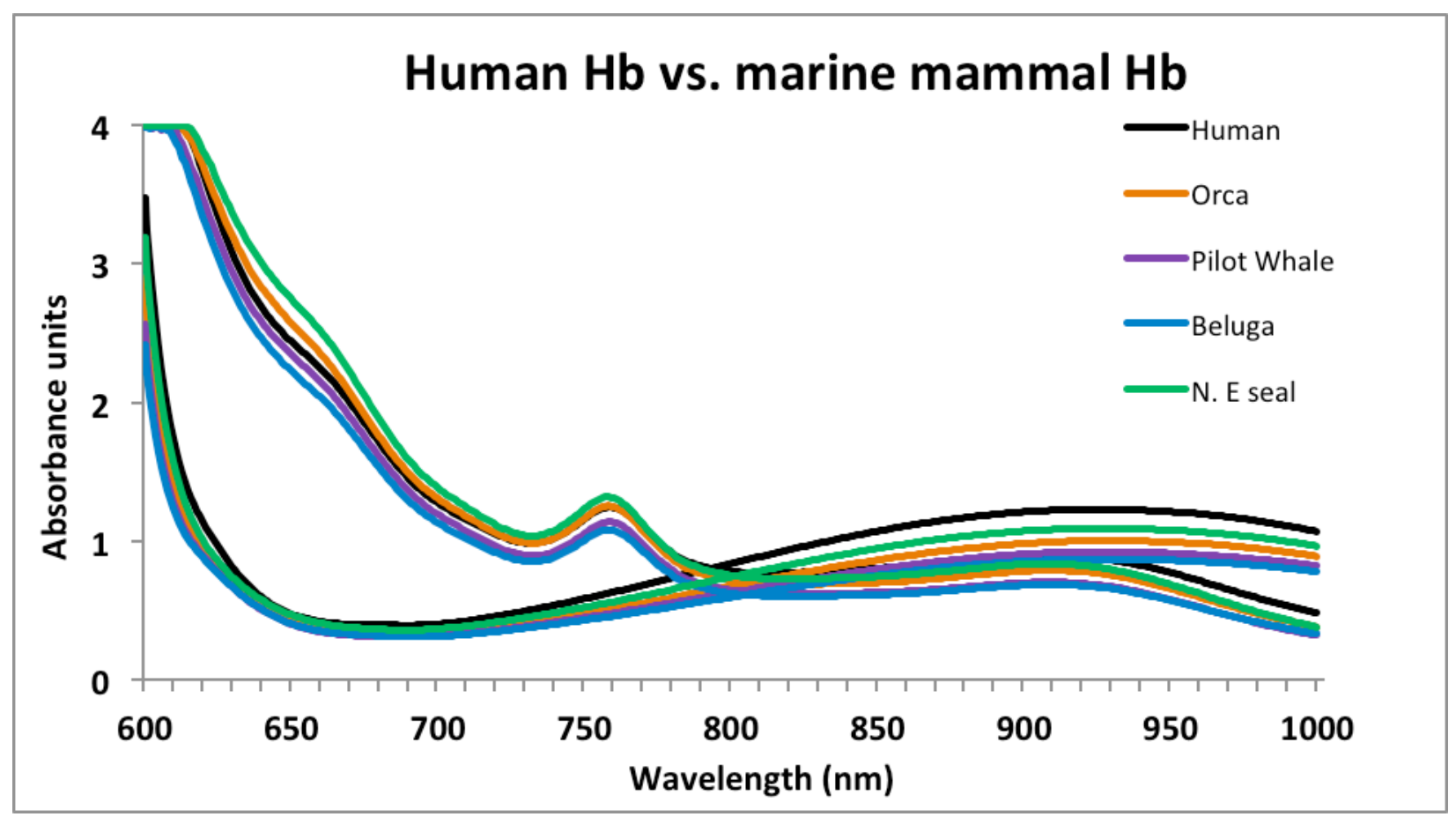

Figure 4. A comparison of the hemoglobin absorption spectra of four marine mammals compared to that of the hemoglobin absorption spectra of humans. The solid lines represent the oxygenated hemoglobin absorption spectra and the dotted lines represent deoxygenated hemoglobin.

Note that all marine mammal species tested have similar characteristic spectra as human and that all isobestic points are $\sim 800 \mathrm{~nm}$. 
Aim 2:

Sensor Implantation and Data Logger Attachment

In April of 2013, elephant seal translocation experiments were conducted to test the ability of a novel sensor and data logger to collect physiological data in vivo in deep diving northern elephant seals.

Animals were sedated on the beach and transported to Long Marine Laboratory where the data logger was attached and the oximeter sensor implanted under injectable sedation. In addition, the implantation procedure of the oximeter was assessed and we carefully noted any indications of trauma or changes in swimming ability to the animal. Woven wires attached the internal sensor and external data logger, which allowed flexibility and movement and prevented sheering of the muscle/blubber interface. Once the sensor and cables were implanted, the cable was secured to the skin at the site where it exited adjacent to the muscle. The data logger was mounted externally using 5 min epoxy (Loctite). The animal recovered overnight and the animal's ability to move and swim assessed. The next morning the seal was transported to Monterey Bay, California, where it was released. The animal swam back to the rookery providing us with physiological diving data stored in the data logger. Once back on the beach, the animal was recaptured and the sensor and data logger removed.

Data Logger Preliminary Results

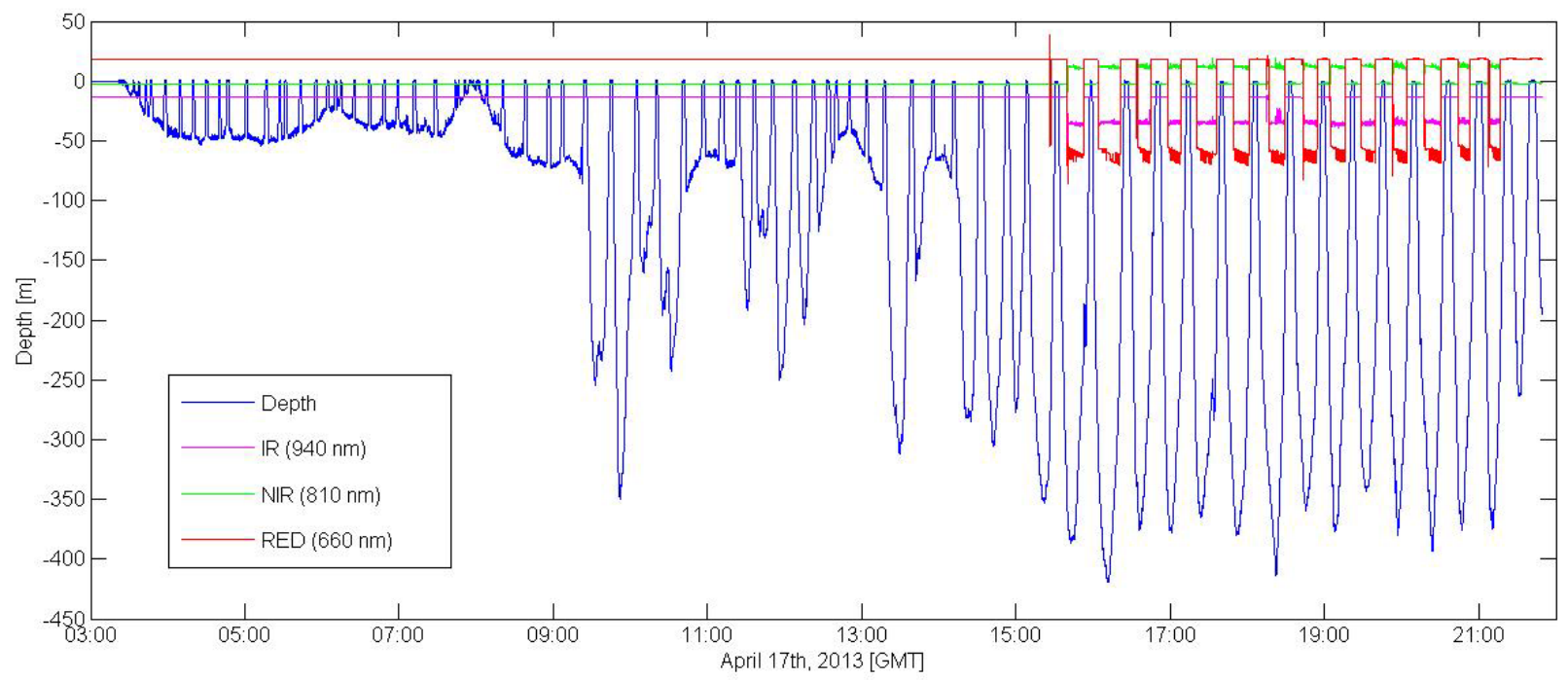

Figure 5. The data collected from a northern elephant seal (G5882) on April 17 ${ }^{\text {th }}$, 2013 over approximately 18 hours while diving freely and equipped with a novel data logging device. The probe implanted into a major swimming muscle (the longissimus dorsi) included an oximeter (for oxygen saturation) that contained a photo detector and 3 LED's emitting light at 660 (visible RED),

810 (near-infrared or NIR), and 940 (infrared or IR) $\mathrm{nm}$ recorded in volts. The data logger contained a pressure transducer that we used to measure dive depth. 


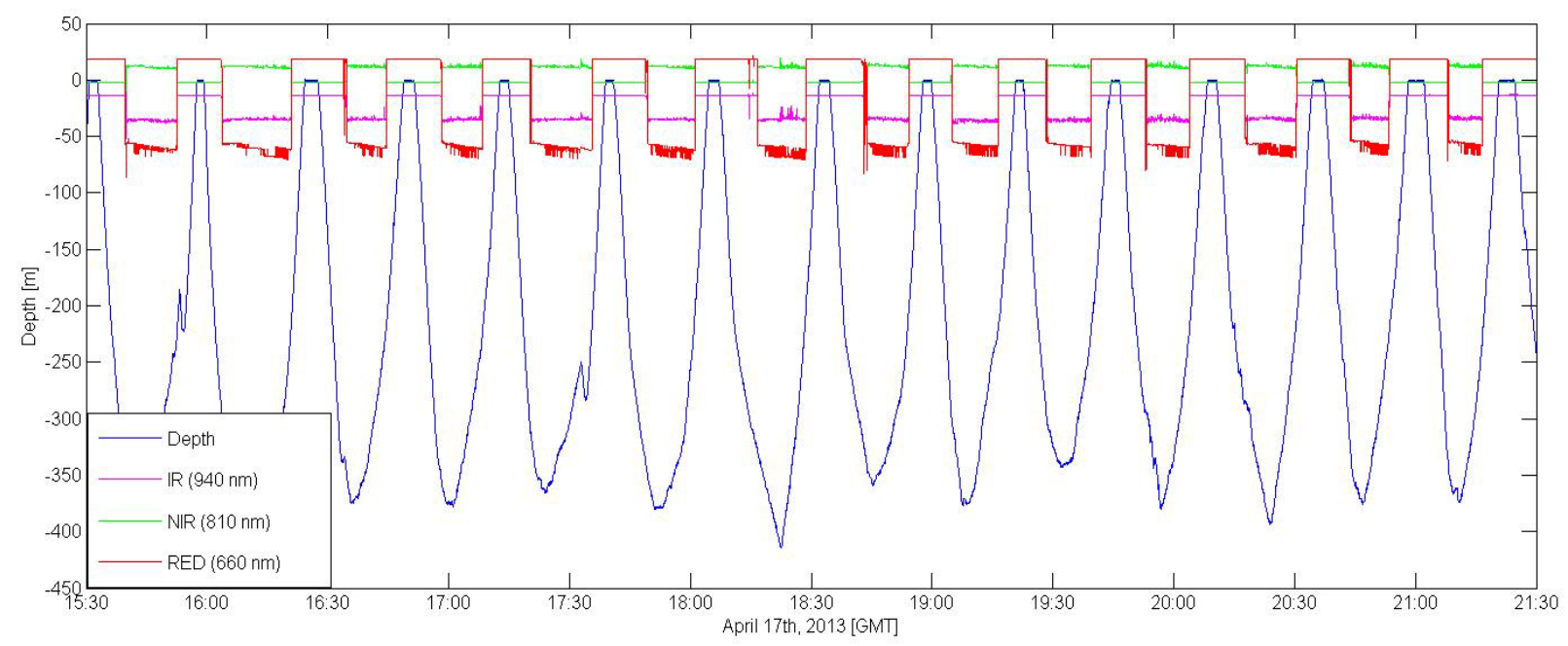

Figure 6. Focused on dives when the sensor came on $\sim 15: 30$ until $\sim 21: 30$ (around the last 1/3) of the data collection time.

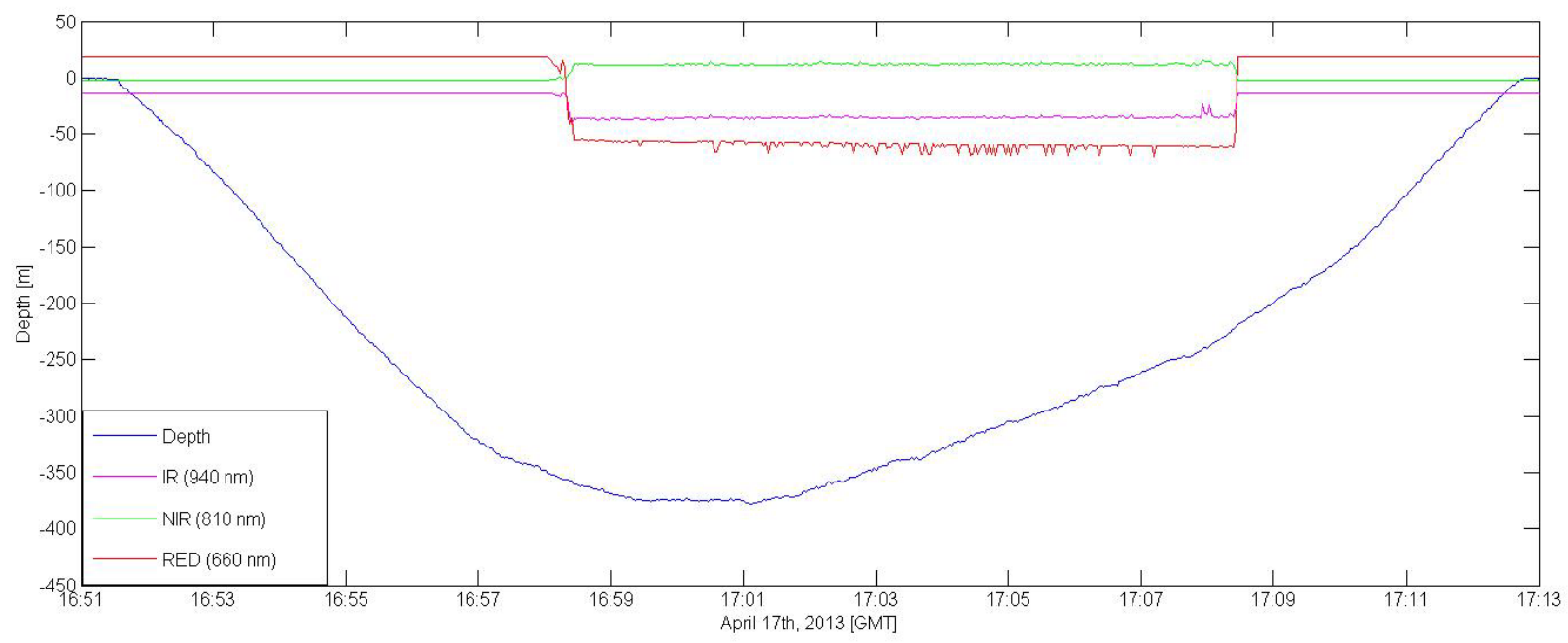

Figure 7. Focused on one dive from $\sim 16: 51$ until end of the dive at $\sim 17: 13$.

The data from the photo sensor are reported as voltages and are therefore inverse of absorption. Thus, a decrease in voltage is increased absorption. Therefore, if the blood/tissues are deoxygenated, more light will be absorbed by them and the voltage will decrease. Conversely, if the blood/tissues are oxygenated, they will absorb less light, resulting in higher reported voltages. As the absorbance is affected by $\mathrm{Hb}$ concentration, the isobestic point serves as an index of changes in blood volume and were used to indicate changes in blood flow. While diving, the blood and tissues are depleted of $\mathrm{O}_{2}$ and there should be minimal blood flow to the peripheral tissues, e.g. muscle. Therefore, we would expect the absorption to increase at $660 \mathrm{~nm}$, remain more or less the same at $800 \mathrm{~nm}$ and decrease at $954 \mathrm{~nm}$, with the voltage going in the opposite direction (Figs. 3 and 4). 
Given that the data indicate that the absorbance at $940 \mathrm{~nm} \mathrm{~nm}$ is behaving opposite to what is expected, i.e. increased instead of decreased absorbance (Figs 5-7), the LEDs were most likely wired backwards. It is interesting to note that the absorbance decreased at $810 \mathrm{~nm}$ possibly suggesting reduced blood volume in the muscle as the dive progresses. Additionally, the LEDs were non-responsive (indicated by the flat lines until $\sim 16: 00 \mathrm{hrs}$ ) during the first $2 / 3$ of the dive. This could indicate that the muscle does not become deoxygenated until a bout of long deep dives. Alternatively, it could suggest additional problems with wiring (Figs. 5-7).

\section{Improvements to be made to sensor and data logger}

Give our experience from the first field season the following improvements will be made:

1. Battery: The battery was located directly beneath the electronic board, which caused several problems. Wire placement makes replacing the battery difficult without damaging or pulling the wires. Also the battery was found to last only $\sim 12-18$ hours. Securing the battery within the housing is of utmost importance, as is extending the battery life.

2. Internal Clock: The previous logger used 3 LEDs and to save battery power the 940nm LED will be removed. Instead, an internal clock will be added to allow the data to be collected with a timestamp.

3. Logger housing and sensor: The logger housing and sensor head must be pressure tested to assure that pressure does not cause shift or "noise" in the data.

4. On/Off switch: The location and design of the magnetic on/off switch will be changed to allow accurate operation and prevent accidentally starting and stopping the data logger.

\section{Aim 3:}

This aim was completed last year and published in a $\mathrm{PhD}$ thesis (Diving physiology in marine mammals: significant findings in pinniped muscle physiology and trachea morphology., https://beardocs.baylor.edu/xmlui/handle/2104/457/browse?value=Moore\%2C+Colby+D.\&type=author).

As marine divers, pinnipeds have a high capacity for exercise at depth and pressure. A large component of that is being more fit for extended aerobic exercise and conservation of energy. Pinnipeds must deal with common physiological hurdles such as hypoxia, exhaustion and acidosiscommon to all exercising mammals. These hurdles have sparked much research in the marine mammal field as to how these diving animals "deal" with onboard carbon dioxide and utilize oxygen stores. In some cases, stranded animals are used in marine mammal research, but can biochemical data derived from post mortem tissues be reliable? In this study, we mapped an enzymatic degradation time series from four biopsied Northern elephant seals (Mirounga angustirostris). We also compared the enzymatic activity of different muscle groups in relation to locomotion as well as measured the effects of four freeze-thaw cycles on a muscle tissue enzyme. Results indicated that enzymatic activity vary depending on the storage temperature, storage time, species and muscle group being assayed. In contrast, proteins, such as myoglobin $(\mathrm{Mb})$, can remain stable at refrigerator temperature. Stranded animals can be a valuable source of biochemical data, but enzyme assays may not be a reliable assay in post mortem tissue. Here, we aim to provide a map of muscle degradation for stranding units collecting post mortem muscle samples and highlight recommendations for storage protocols for the best preservation of tissue. Ultimately, we aim to determine the reliability of biochemical assays derived from post mortem tissue, and further promote the immediate sampling of stranded animals for the purpose of physiological research. 


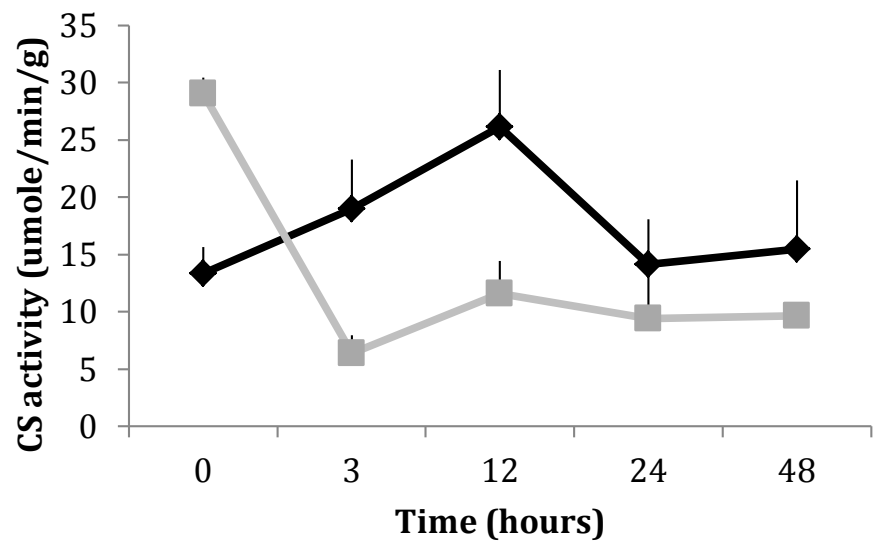

Figure 1: Citrate synthase activity level (umole/min/g) $\pm S D$ in the longissimus dorsi muscle of 4 Northern elephant seal adult males. Measurements were made over 48 hours at two different temperatures (black $4^{\circ} \mathrm{C}(\mathrm{M3}, \mathrm{AM} 12)$ and gray $\left.21^{\circ} \mathrm{C}(\mathrm{AM} 13, \mathrm{M4})\right)$ indicating the greater stability of the enzyme at $4^{\circ} \mathrm{C}$ versus $21^{\circ} \mathrm{C}$ in biopsied muscle tissue. $N=4$.

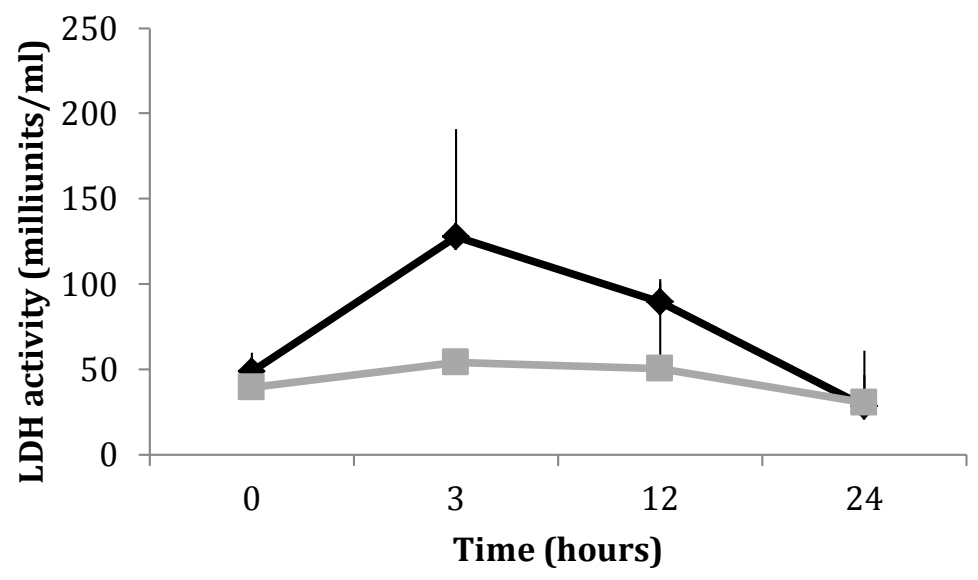

Figure 2: Lactate dehydrogenase activity level (miliunits/ml) $\pm S D$ in the longissimus dorsi muscle of 4 Northern elephant seal adult males. Measurements were made over 24 hours at two different temperatures (black lines at $4^{\circ} \mathrm{C}$ and gray lines at $21^{\circ} \mathrm{C}$ ) indicating the greater stability of the enzyme at $4^{\circ} \mathrm{C}$ versus $21^{\circ} \mathrm{C}$ in biopsied muscle tissue. $N=4$. 


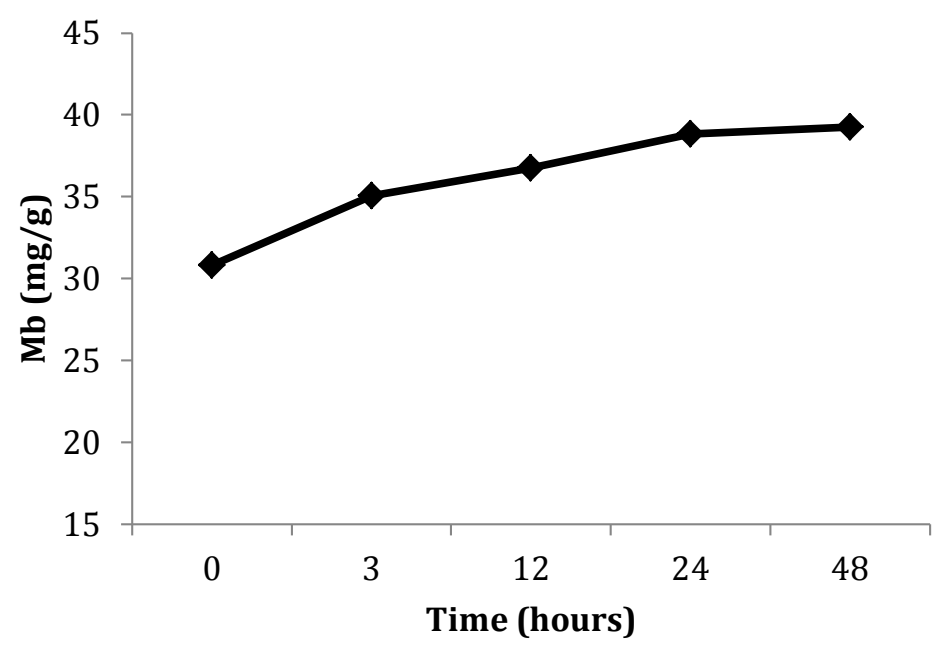

Figure 3: Northern elephant seal (ES3289) measured over 48 hours at $4^{\circ} \mathrm{C}$ for degradation of myoglobin $(\mathrm{mg} / \mathrm{g}) \pm S D$. The figure indicates the relative stability of myoglobin when maintained at $4^{\circ} \mathrm{C}$. $N=1$.

\section{IMPACT/APPLICATIONS}

This work is intended to enhance our understanding of how the dive response alters muscle blood flow and metabolism in large, freely diving whales. The results will provide information that will enable more realistic predictions of how the dive response varies during breath-hold diving in different activities. The aim of this study is provide data to generate a new generation of data loggers that are able to collect physiological data in large whales with minimal impact.

Results from the completed study will help to improve our understanding of the physiology of marine mammals and improve modeling efforts that are aimed at estimating inert gas levels in breath-hold divers. The results can be used to determine how changes in dive behavior, from playback studies that measures avoidance patterns in deep diving whales, affect blood and tissue $\mathrm{P}_{\mathrm{N}_{2}}$ levels. Thus, our results will enhance the fundamental understanding, interpretation and avoidance of the effect of anthropogenic sound, and enable knowledgeable decisions about sonar deployment, related training exercises and responses to NGO concerns. This should be of value to the US Navy Marine Mammal Program.

\section{REFERENCES}

Guyton, G. P., K. S. Stanek, R. C. Schneider, P. W. Hochachka, W. E. Hurford, D. G. Zapol, G. C. Liggins and W. M. Zapol (1995). "Myoglobin saturation in free-diving Weddell seals." Journal of Applied Physiology 79: 1148-1155.

Meir, J. U. and P. J. Ponganis (2009). "High-affinity hemoglobin and blood oxygen saturation in diving emperor penguins." Journal of Experimental Biology 212(20): 3330-3338. 